https://doi.org/10.48009/1_iis_2007_59-64

\title{
FINDING LIGHT AT THE END OF THE GRADUATION TUNNEL
}

\author{
Bryan Marshall, Georgia College and State University, bryan.marshall@gcsu.edu \\ Peter Cardon, University of South Carolina, pcardon@gwm.sc.edu \\ Tanya Goette, Georgia College and State University, tanya.goette@gcsu.edu \\ Natalya Goreva, Indiana University of Pennsylvania, natalya.goreva@iup.edu
}

\begin{abstract}
This paper identifies some key attributes Information System (IS) graduates should be aware of in their quest to find a job. In looking at over 330 job postings on Monster.com and Dice.com, we found that there are three things employers want in their new hires: education, certification, and experience. In this paper we develop a rationale for motivating IS students to graduate, take internships, and get certified.
\end{abstract}

Keywords: Curriculum Development, Experience, Education, Certification, Information Systems

Note: We should mention that this paper is not intended to motivate departments to adopt or require a certificate program, but instead to motivate faculty to encourage students to seek certification and real world experience on their own.

\section{INTRODUCTION}

\section{Job Market}

During the height of the dot com boom, it was estimated that there would be 12 job openings for every graduate $[3,7]$. However, in recent years, this has not been the case. Students are struggling to get jobs after graduation and lack confidence in their abilities. Research shows there are three main prerequisites critical to increasing the possibilities for employment after graduation: a college education, real world relevant experience, and certifications [8].

In a report by the U.S. Department of Labor in 2004, employment in professional, scientific, and technical services will grow by 28.4 percent and add 1.9 million new jobs by 2014. Employment in computer systems design and related services will grow by 39.5 percent and add almost one-fourth of all new jobs in professional, scientific, and technical services. Employment growth will be driven by the increasing reliance on businesses on information technology and the continuing importance of maintaining system and network security. Management, scientific, and technical consulting services also will grow very rapidly, by 60.5 percent, spurred by the increased use of new technology and computer software and the growing complexity of business.

In 2001, the Bureau of Labor Statistics projections for the period 2000-2010, of the 10 fastest growing occupations, computer-related occupations occupy eight of the top ten positions: software applications engineers, support specialists, systems software engineers, network and systems administrators, network systems and data communications analysts, desktop publishers, database administrators, and systems analysts [7].

Today, these numbers have dropped to 7 of the top 25 positions: network systems and data communication analyst, computer software engineers (applications), computer software engineers (system), network and computer system administrators, database administrators, forensic science technicians, and computer system analysts [2]. On a side note, each of these 7 jobs were classified within the highest salary classification of the U.S. Department of Labor.

Many times students graduate from college with little or no real world experience and are not viewed as ready to succeed in some of these jobs. One of the options available that may increase a student's chance of getting that job is certification. Certification is the proof that many employers may desire to assure that their new employee meets a minimum standard.

\section{Certification Research}

The choice of requiring student certification has been debated. Some say that the role of certification falls to the technical schools and that the main role of the universities is teaching theory. Others claim that certifications are too vendor specific and thus detract from providing students with a strong theoretical background. Some even claim that because there are 
so many certifications, they have become watered down and diluted [8].

There are some academic fields that teach directly to the certification, such as accounting, education, and even nursing. These fields teach to certification exams because without the certification the graduate would not be able to get a job at all [10]. However, prior research shows that only 20 percent of Information Technology jobs require certification [1, 9].

Some research has shown the importance of vendor specific certifications and even integrated them into the curriculum. In 2006, White introduced a four course curriculum focused on computer networking and security using the following certifications: Network+, MCP, MCSE, CCNA, CCNP, Security+, CISSP.

White makes the point that certifications show the students know 'how'. He elaborates that a college degree shows the students know 'why'. He also mentions that certifications alone can get a job candidate an entry level job. However, if the employee then wants to move up to management, a college degree is essential [11].

A leading computer security graduate program requires its graduates to pass a series of security certifications before graduation (personal communication, Richard Swart, July 15, 2006).

With the brain dumps and other resources available on the internet, an argument could be made that one could get certified without actually knowing anything. Quan et al [9] cite an argument that some high school program graduates are graduating with certificates already. What value then does a college degree actually have?

\section{College Degree}

Earlier, we mentioned that 7 of the top 25 fastest growing jobs were in information technology. All of these but one required at least a bachelor degree to be considered "fully qualified" [2].

At the college level, the focus by professors of preparing the students is primarily on the curriculum. Most professors understand the importance of teaching relevant material that students will need in getting jobs, especially in the rapidly changing fields. This is illustrated by the constant curriculum changes and updating of textbooks. Professors understand the importance of giving the students concrete theory along with hands-on practice to imbed the theory.

However, upon graduation some students seem to lack the confidence employers are looking for in college grads. One way for students to increase their confidence would be a certification in their chosen field. However, research has shown that certifications are not widely accepted by universities as relevant methods of instruction. Instead, universities consider certifications a role for technical colleges. However, the purpose of this paper is to 1) show the importance of certifications and 2) discuss ways to incorporate this importance into discussions with the students to motivate them to get certified.

\section{RESEARCH METHODOLOGY}

Our research centered upon the following research questions:

1. What real value does professional certification have on employability?

2. What real value does experience have on employability?

3. What real value does education have on employability?

4. What percentage of jobs require certification when searching with the generic terms?

To answer these questions a series of data collections were completed using Monster.com and Dice.com, two of the most popular job search engines.

\section{Research Design}

To examine the salaries, experience requirements, and education requirements of certification focused jobs, a search was completed using the following terms:

Certification Terms:

- OCP (Oracle Certified Professional)

- MCSE (Microsoft Certified Systems Engineer)

- $\quad$ CCNA (Cisco Certified Network Administrator)

- $\quad \mathrm{A}+$ (Hardware and Software Exam)

- CISSP (Certified Information Systems Security Professional)

- $\quad$ PMP (Project Management Professional)

We did not find any prior research focusing on the certification as the search term only. Instead the focus had always been on a more generic Information Technology term $[4,6,8]$. On a side note, when searching the certification terms, more information 
was generally available on each job announcement. Meaning that employers looking for certified individuals were very specific in describing the exact job for which they were hiring.

In an attempt to create a baseline, an equally large search was completed using generic search terms. These search terms were extracted from the IS 2002 Curriculum [5].

\section{Generic Terms}

- Database

- Computer Security

- Hardware Support

- Networking

- Project Management

Each term was searched individually. Only nonduplicate job postings were used. A total of 330 different job postings were analyzed for the required education, experience, salary, and certifications.
In this section we attempt to answer the research questions.

1. What real value does professional certification have on employability?

The jobs that required a certification generally paid much higher salaries. In each case, each job type paid about \$20,000 more each year with certification compared to those without, with the exception of the A+ Exam (Figure 1). If you had the A+ Exam, you would make significantly less than someone who did not. This could be explained by the nature of the certification. The A+ Exam is an entry level job certification. The correlated search term was hardware support. The hardware support jobs required much more education and experience.

If we were to rank the jobs by salary, the highest paid would be computer security, project management, database administration, computer networking, and then hardware support.

\section{RESULTS}

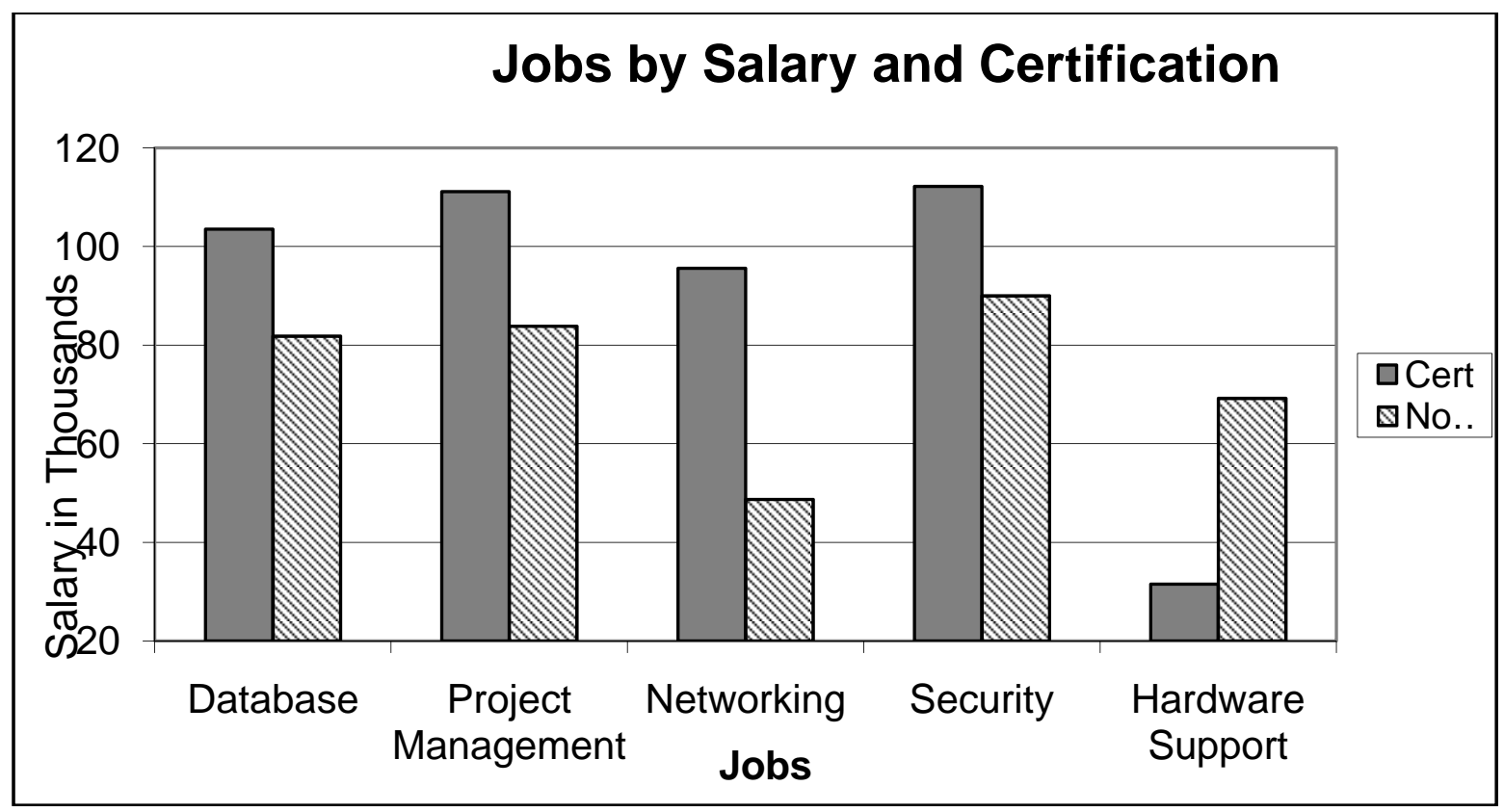

Figure 1. Jobs by Salary and Certification

2. What real value does experience have on employability?

Each of the jobs required within one year of experience for both the certified and uncertified positions, except for hardware support $(\mathrm{A}+)$ and security (CISSP). We have already discussed the discrepancies with hardware support. However, this finding supports our prior claims of reasons for a higher salary without a certification in hardware support. 
The research showed that more experience was required for the higher paying jobs in computer security, if you had your CISSP. The CISSP is considered the gold standard of computer security certifications. Before a person can even sit for this exam, they must have five years of experience in computer security. The required experience for security without the CISSP certification is only 3.7 years. The required experience with the CISSP is 5.83 , which validates this research to the extent that it is higher than five years. Maybe this shows that those seeking CISSP's, at an average salary of $\$ 112,000$, know what it takes to get that certification.
In the other areas, database experience was 6.33 years with certification and 5.37 without. Project management required 7.10 years with certification and 6.65 without while networking needed 5.30 years with certification and 5.59 without. As shown in Figure 2, all jobs had very similar experience requirements for those with and without certification requirements.

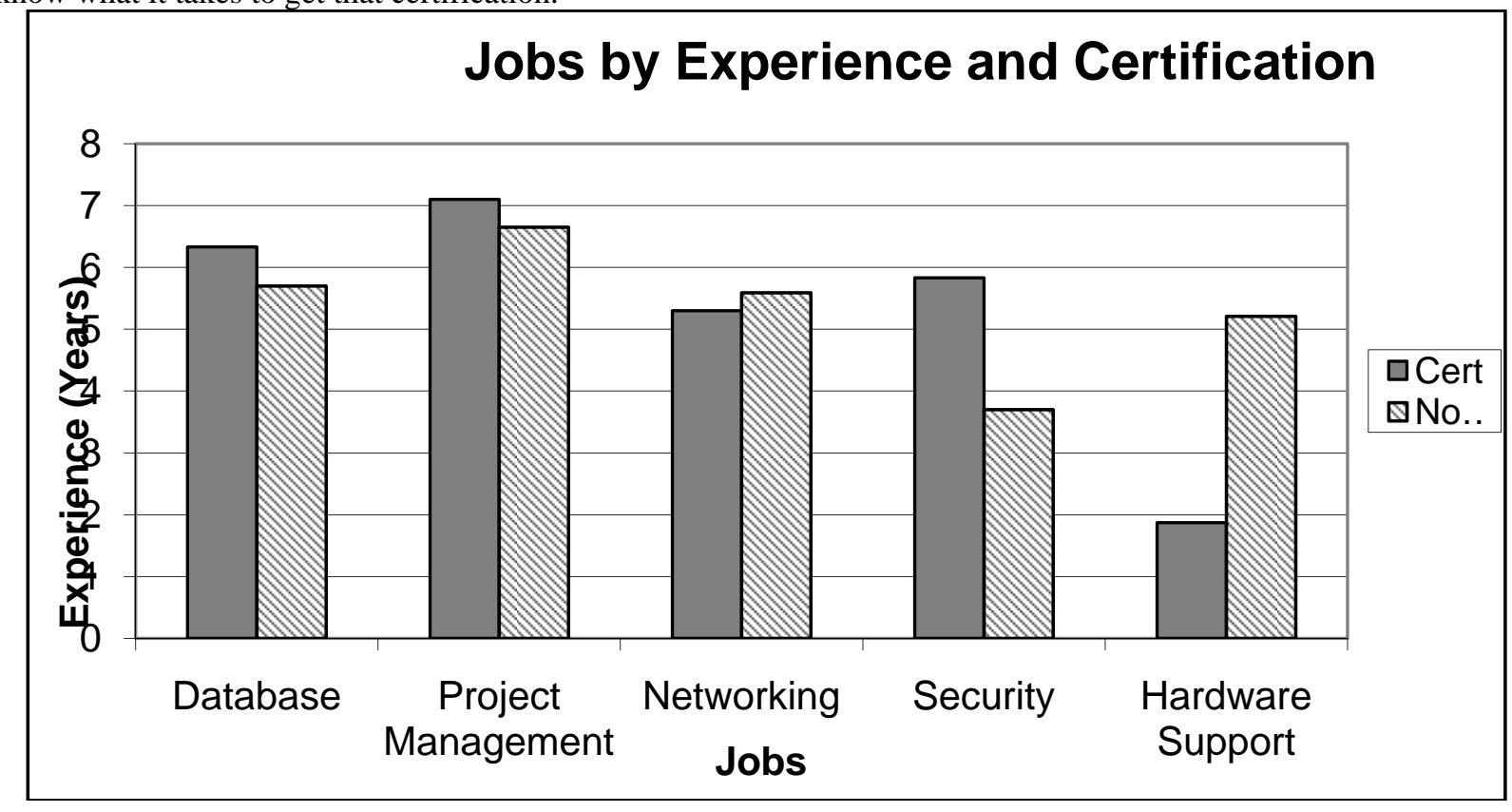

Figure 2. Jobs by Experience and Certification

3. What real value does education have on employability?

Database administration (4.13 years of school with a certification and 3.9 without), project management (4 years of school with a certification and 3.83 without), and security (3.8 years of school with a certification and 3.0 without) all required at least a bachelor degree for both certificate and non certificate jobs.

Without a certification in networking (CCNA), the average job required close to 3.64 years of education or a bachelor degree, which correlates with what the U.S. Department of Labor states. However, if you have a CCNA certification, the average job in networking only requires 2.2 years or an associate's degree.
This is similar to the hardware support job where the $\mathrm{A}+$ certification jobs only required .33 years of school, which is about the time required at a trade school to get the certification. However, to get the higher pay in hardware support you needed to have completed almost 3 years of school. The traditional technical school or community college, where you would earn your A+, CCNA or MCSE, generally has only two year programs.

The argument could be made that is better to not be certified, and then you don't have to have as much school, as seen in Figure 3. However, to get the higher paying jobs you must have at least a bachelor degree with certification as seen in Figure 1. 


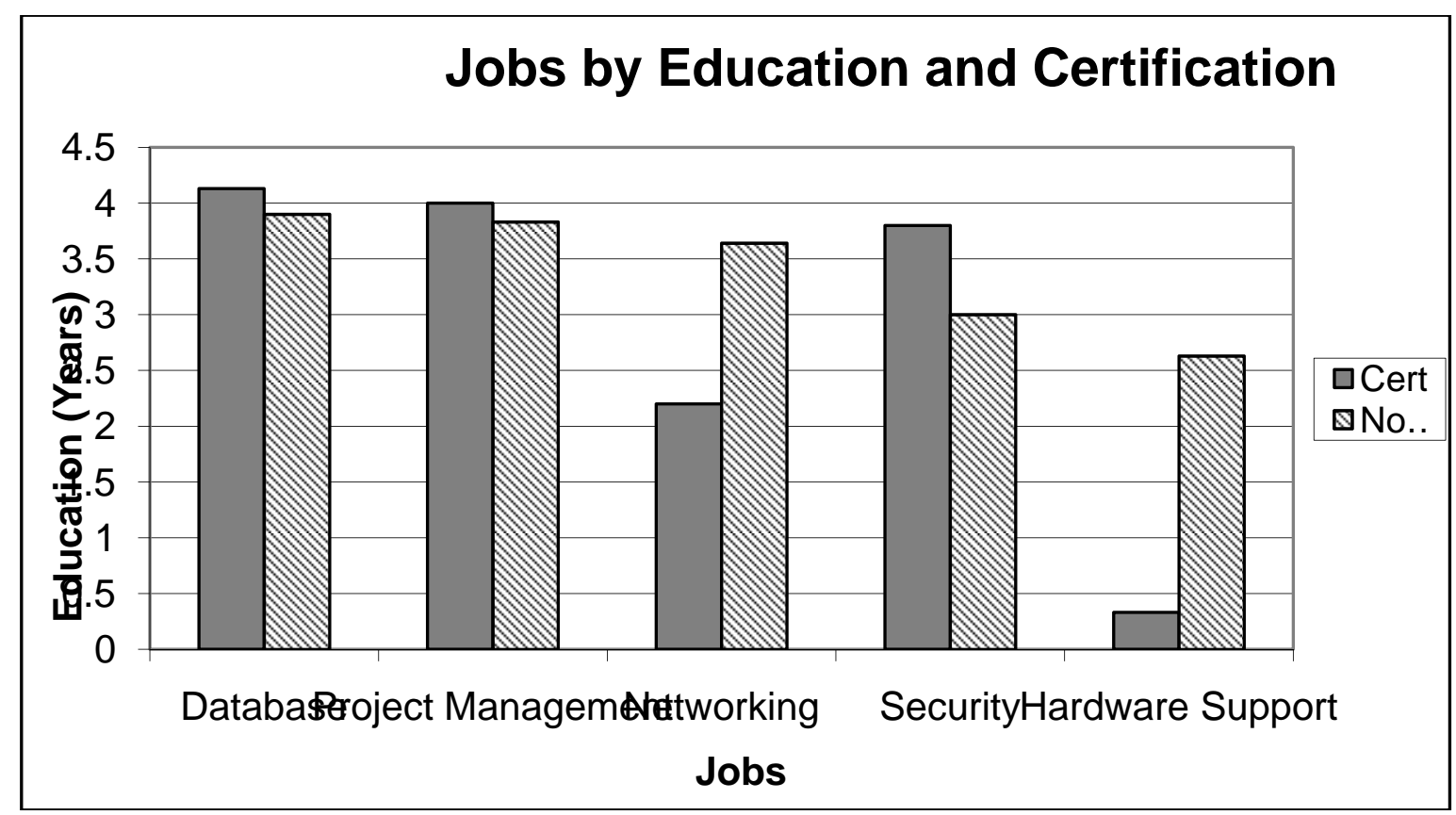

Figure 3. Jobs by Education and Certification

4. What percentage of jobs require certification when searching with the generic terms?

Previous research reported that only $20 \%$ of jobs searched required a certification $[1,9]$. For the most part, each job area searched returned a requirement for certification around $20 \%$ of the time. Thus, this research agrees with the previous findings. The number of jobs requiring certification was. database (20\%), project management (23\%), networking (27\%), and hardware support (37\%).

However, $67 \%$ the security jobs posted on dice.com and monster.com required certification. This correlates with the knowledge that certification is more of a necessity in the networking field.

As expected, we found $100 \%$ of jobs searched with the certification name in the search field required certification. Perhaps future research could examine how students are searching for jobs in Information Technology. Do students looking for jobs enter the generic search terms or do they enter certification information?

\section{CONCLUSIONS}

This research re-solidified the theory that certification, experience, and education are all important factors to increase employability and increase salary. Students need to understand the importance of experience and certification in the areas that they wish to explore.

Many departments understand the importance of real world experience for their students. These departments require some type of internship (paid or unpaid) before graduation. These internships become valuable training tools for the students and may lead to full time employment after graduation.

In addition to internships, certification may be a way for students to increase their confidence and have more doors opened to them as they search for jobs in the IT field. College professors should make students aware of the certifications that are available within each area. They should also point students to information on becoming certified and encourage them to explore on their own the differences in job availability and salaries for positions requiring certification. 


\section{Percentage of Jobs (Using Generic Terms) Requiring Certificaiton}

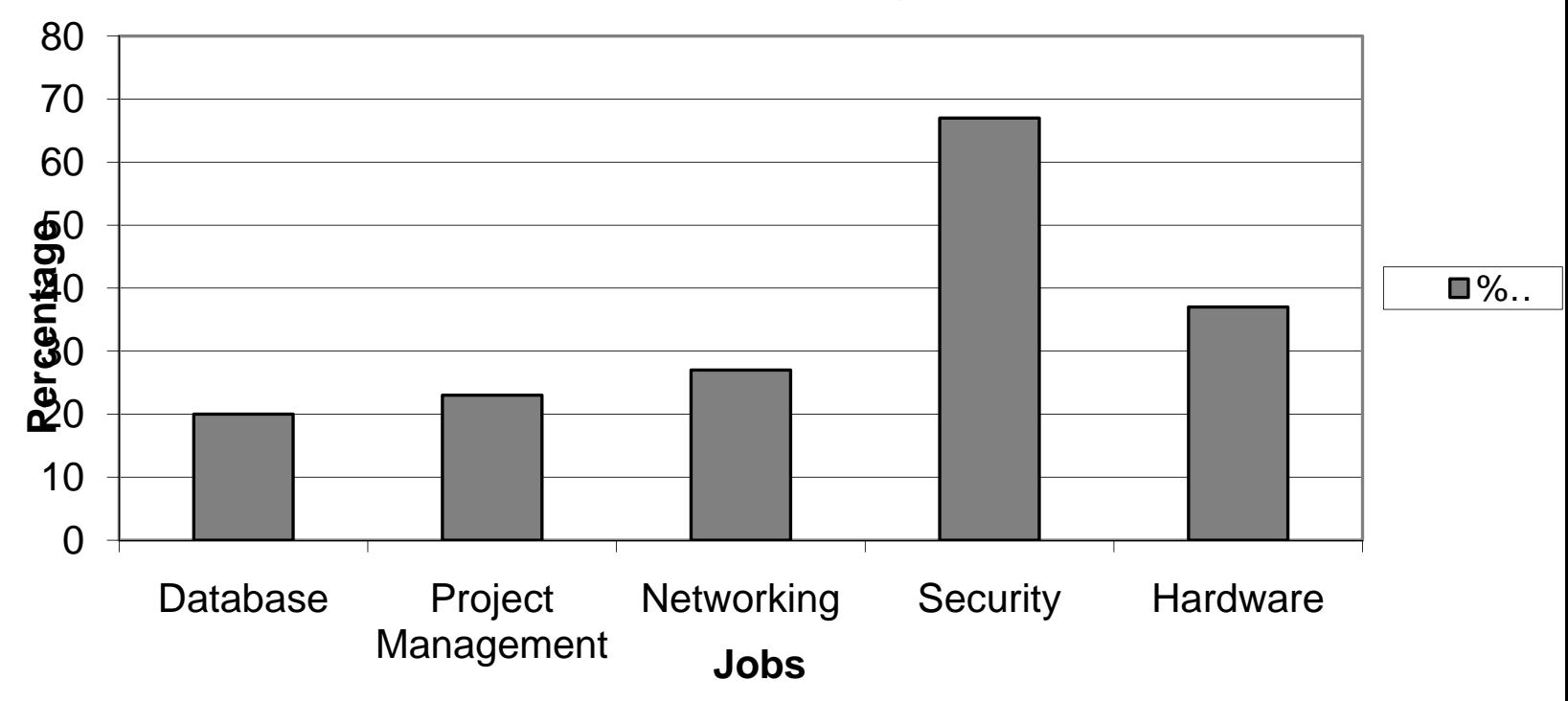

Figure 4 - Percentage of Jobs Using Generic Terms Requiring Certification

\section{REFERENCES}

1. Bailey, J. L., \& Stefaniak, G. (October, 1999). Preparing the information technology workforce for the new millennium. ACM SIGCPR Computer Personnel, 20(4).

2. Bureau of Labor Statistics. (2004). Fastest Growing Occupations 2004-2014 "Table 2". November 2005 Monthly Labor Review. Available: http:/www.bls.gov/emp/ emptab21.htm

3. Ehie, I. (2002). Developing a MIS Curriculum: Perspectives from MIS practitioners. Journal of Education for Business, 77(3), 151.

4. Gjestland, C. Blanton, J. E., Will, R., \& Collins, R. (2001). Assessing the Need for Training in IT Professionals: A Research Model. Proceedings of the 2001 ACM SIGCPR Conference on Computer Personnel Research SIGCPR '01, 212214.

5. Gorgone, J., Davis, G., Valacich, J., Topi, H., Feinstein, D., \& Longenecker, H. Jr. (2002)._IS 2002 Model Curriculum and Guidelines for Undergraduate Degree Programs in Information Systems. ACM, New York, NY, AIS, and AITP (formerly DPMA), Park Ridge, IL.

6. Leitheiser, R. L. (Summer, 1992). MIS Skills for the 1990s: A Survey of MIS Managers' Perceptions. Journal of Management Information Systems, 9(1).
7. Noll, C., \& Wilkins, M. (2002). Critical Skills of IS Professionals: A Model for Curriculum Development. Journal of Information Technology Education, 1(3), 143-154.

8. Quan, J., Dattero. R., \& Galup, S. T. (2007). Information Technology Wages and the Value of Certifications: A Human Capital Perspective. Communications of the Association of Information Systems, 19, 81114.

9. Rollier, B. (2002). Preparing MIS students for a global economy. Journal of Information Systems Education, 12(4), 193200.

10. Schlichting, C., \& Mason, J. (2004). Certification Training and the Academy. The Journal of Computing Sciences in Colleges, 20(1), 157-167.

11. White, R. (2006). Vendor/Industry Certifications and a College Degree: A Proposed Concentration for Network Infrastructure. Information Systems Education Journal, 4(48), 1-7. 